\title{
Effects of Ultrasonic Parameters on the Crystallization Behavior of Virgin Coconut Oil
}

\author{
Linhe Wu, Jun Cao, Xinpeng Bai* , Haiming Chen, Yuxiang Zhang and Qian Wu \\ College of Food Science and Engineering, Hainan University, Haikou 570228, CHINA
}

\begin{abstract}
Crystallization behavior of virgin coconut oil (VCO) in the absence and presence of ultrasonic treatment under a temperature gradient field was investigated. The effects of ultrasonic parameters on the crystallization behavior of VCO were studied by differential scanning calorimetry, ultraviolet/visible spectrophotometry and polarized light microscopy. The thermal effect of the ultrasonic treatment was also increased at higher power levels. Therefore, the optimal power level was determined at approximately $36 \mathrm{~W}$. Induction time reduced evidently and the crystallization rate was accelerated under ultrasonic treatment at crystallization temperature $\left(T_{c}\right)$ above $15^{\circ} \mathrm{C}$. However, no significant difference in induction time was noted at $13^{\circ} \mathrm{C}$. The result of morphological studies showed that the growth mechanism of crystals was significantly changed. Meanwhile, smaller and uniform crystals were produced by the ultrasonic treatment. This study shows a novel technique to accelerate the crystallization rate and alter the growth mechanism of VCO crystals.
\end{abstract}

Key words: virgin coconut oil, ultrasonic treatment, temperature gradient, crystallization, kinetics

\section{Introduction}

Virgin coconut oil (VCO) is obtained from mature kernel of the coconut ${ }^{1,2)}$. VCO is produced by natural technique without chemical refining. It has some specific functional properties when compared with that of the refined one. Therefore, VCO is widely utilized in the food industry for its higher oxidative stability and specific functional properties. For the beneficial properties, VCO have attracted considerable attentions, especially in Southeast Asia.

VCO typically exists in liquid state above $25^{\circ} \mathrm{C}$. Clear VCO becomes turbid and gradually transforms into a white solid fat state when the temperature below $25^{\circ} \mathrm{C}$. The characteristics of high-melting-point limit the application of VCO. However, Oil modification can separate the high- and low-melting-point fractions of $\mathrm{VCO}$, and improve its values. High-melting-point fractions provide stabilities in high-fat products, such as cookies and chocolate, for avoiding the melting process at specific temperatures. Meanwhile, lowmelting-point fractions can be used in producing healthcare products and daily necessities ${ }^{3)}$. Crystallization in a temperature gradient field is a new and promising technique $^{4,5)}$. This approach is considered environmental friendly and cost-effective because it involves a physical process based on the crystallization of melted materials in the absence of chemical addition ${ }^{6)}$. Ultrasonic employs sound wave frequencies above $20 \mathrm{kHz}$. Owing to its favorable characteristics, such as high stability, simple operation, and low environmental hazard, ultrasonic is widely used in emulsification, extraction, crystallization, homogenization, and filtration ${ }^{7)}$. In addition, ultrasonic has been used to modify the crystallization behavior of different edible oil. The effects of ultrasonic treatment on edible oil crystallization can be summarized as follows: (1) promoting crystal nucleus formation, (2) accelerating crystal growth, (3) altering material crystallization mechanism and (4) hastening the crystallization process ${ }^{8,9)}$. Ultrasonic treatment not only shortened the nucleation induction time and accelerated the growth rate of palm oil crystals, but also altered the mechanism of crystal formation and generated homogeneous crystal grains ${ }^{10}$. Ultrasonic application obviously affected oil crystal microstructure in terms of crystal cluster shape and size ${ }^{11,12)}$. Concurrently, ultrasonic treatment promoted crystal transformation from the unstable to

Abbreviations: C6:0, Hexanoic acid, C8:0, Caprylic acid, C10:0, Capric acid, C12:0, Lauric acid, C14:0, Myristic acid, C16:0, Pamitic acid, C18:0, Stearic acid, C18:1, Oleic acid, DSC, Differential scanning calorimetry, PLM, Polarized light microscopy, p-NMR, Pulsed nuclear magnetic resonance, $T_{c}$, Crystallization temperatures, SFC, Solid fat content, UVS, Ultraviolet/visible spectrophotometry, VCO, Virgin coconut oil.

\footnotetext{
*Correspondence to: Xinpeng Bai, College of Food Science and Engineering, Hainan University, Haikou 570228, CHINA

E-mail: xinpeng2001@126.com

Accepted July 25, 2016 (received for review April 12, 2016)

Journal of Oleo Science ISSN 1345-8957 print / ISSN 1347-3352 online

http://www.jstage.jst.go.jp/browse/jos/ http://mc.manusriptcentral.com/jjocs
} 
the stable state ${ }^{13)}$. Although ultrasonic has been used in the crystallization of different lipids, little information is available about the effects of ultrasonic application on the crystallization behavior of VCO.

This study mainly aimed to investigate the effects of ultrasonic conditions on the crystallization behavior of VCO using a temperature gradient field apparatus. Ultraviolet/ visible spectrophotometry (UVS), differential scanning calorimetry (DSC), and polarized light microscopy (PLM) were used to measure the induction time, thermodynamic properties and morphology of VCO. The Avrami equation was employed to study the crystallization mechanism of $\mathrm{VCO}^{14)}$.

\section{Materials and methods}

\subsection{Preparation of sample}

Mature coconuts were purchased from Coconut Research Institute, Chinese Academy of Tropical Agricultural Sciences (CATAS). VCO was extracted from coconut kernels by using aqueous enzymatic method ${ }^{15)}$. Grated coconut meat was combined with some water, placed in a water bath, incubated for a certain time period under the desired $\mathrm{pH}$, temperature, and enzyme concentration. Afterward, the mixture was centrifuged, the water layer was discarded, and the oil fraction, which is the VCO, was collected.

\subsection{Reagents and standards}

Cellulase (100 U/mg), hemicellulase (100 U/mg) and papain (100 U/mg) were purchased from Shanghai Wee-Beyond Scientific \& Trade Co. (Shanghai, China). Methanol (HPLC grade), $n$-hexane (HPLC grade) and 98\% sulfuric acid (analytical grade) were purchased from Guangzhou Xilong Chemical Co. (Guangzhou, China). Fatty acid methyl esters (FAMEs) 37 components standard mix were obtained from Sigma Chemicals Co. (Deisenhofen, Germany).

\subsection{Fatty Acid analysis}

VCO was totally melted at $60^{\circ} \mathrm{C}$. Fatty acid methyl esters were prepared according to the Method of Waller et $a l^{16}{ }^{16)}$, and analyzed by gas chromatography (Model 7890A, Agilent Technologies) equipped with a flame ionization detector (FID), and a capillary chromatographic column (DB-WAX) . The split ratio was 10:1. Injection and detector temperatures were set at $250^{\circ} \mathrm{C}$. The initial oven temperature was $80^{\circ} \mathrm{C}$ for $2 \mathrm{~min}$, then increased to $240^{\circ} \mathrm{C}$ at a heating rate of $3{ }^{\circ} \mathrm{C} / \mathrm{min}$ and maintained for $15 \mathrm{~min}$. Nitrogen (purity 99.99\%) was used as the carrier gas at a flow rate of $25 \mathrm{~mL} /$ min. Fatty acids were detected by chromatographic retention time by comparison with authentic standards. The final results are expressed as relative percentage of peak area.

\subsection{Isothermal crystallization analysis}

The VCO samples were induced to undergo isothermal crystallization using a DSC instrument(model Q100, TA, USA). VCO (5-10 mg) was conditioned at $60^{\circ} \mathrm{C}$ for $10 \mathrm{~min}$ to destroy crystal memories and then rapidly cooled down at a rate of $10^{\circ} \mathrm{C} / \mathrm{min}$ to an isothermal holding temperature $\left(13-19^{\circ} \mathrm{C}\right)$, which was maintained for $30 \mathrm{~min}$. Next, the sample was heated at a rate of $2^{\circ} \mathrm{C} / \mathrm{min}$ to define the melting endotherm. Therefore, all thermograms were performed using the same sample ${ }^{17)}$. Solid fat content (SFC) is an important value which measures the ratio of fat in crystalline form to liquid at various specified temperatures, which was determined by DSC. The melting point of the samples was taken from the peak temperature of the reheating cycle. The values of VCO given in this work are referred to $25.0 \pm 0.1^{\circ} \mathrm{C}$. It possessed a solid fat content of $48.0 \%$ at $19^{\circ} \mathrm{C}$ (Fig. $2 \mathrm{a}$ ).

\subsection{VCO crystallization using a temperature gradient field apparatus}

A temperature gradient field device (Fig. 1) is an apparatus used to separate high- and low-melting-point oil fractions; it mainly consists of a temperature control system, ultrasonic generator, thermostatic bar, and double-wall beaker. The system is controlled by the temperature controller, and the interlayer of double-wall breaker is filled with circulating water that stabilizes the temperature for a long period. Meanwhile, a beaker full of VCO is placed in the ultrasonic generator.

VCO was crystallized at different crystallization temperatures $\left(T_{c}=13,15,17\right.$ and $19^{\circ} \mathrm{C}$, respectively). Three sets of the temperature gradient field equipment were operated

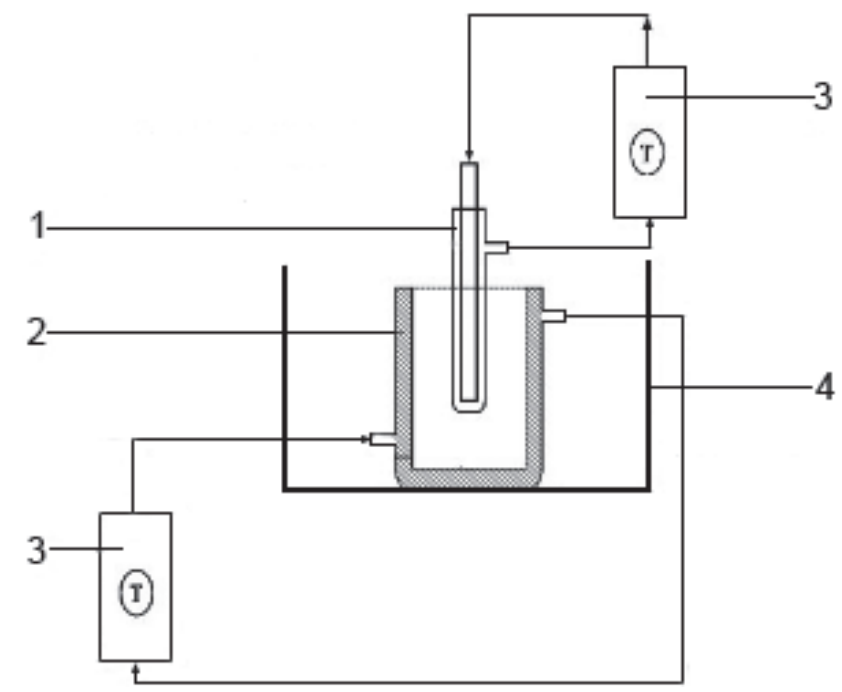

Fig. 1 Schematic of the temperature gradient field apparatus. (1) thermostatic bar; (2) interlayer of double breaker; (3) temperature controlling system; (4) ultrasonic generator. 
under identical conditions to ensure the accuracy of experiments. VCO $(50 \mathrm{~g})$ was conditioned at $60^{\circ} \mathrm{C}$ for $10 \mathrm{~min}$ and then poured into a $100 \mathrm{~mL}$ double-wall beaker. The temperature of beaker was set to a desired constant temperature, whereas the temperature of thermostatic bar was maintained constantly at $35^{\circ} \mathrm{C}$. The thermostatic bar was subsequently dipped into the melt, and the temperature of melt was measured during crystallization by the thermostatic bar. After $1 \mathrm{~h}$, the thermostatic bar and the melt were removed from the double-wall beaker, and the double-wall beaker was heated up to $25^{\circ} \mathrm{C}$ (melting point of coconut oil) to remove the adhering liquid phase from the cold surface. The solid fraction was then weighed several times until the end of test at $9 \mathrm{~h}$.

\subsection{Ultrasonic assay}

Ultrasound $(40 \mathrm{kHz})$ was applied as soon as the pre-cooling stage was finished. Samples were sonicated at $40 \mathrm{kHz}$ using the temperature gradient field device at different power levels (12, 36 and $60 \mathrm{~W}$, respectively). During sonication, the sample temperature was measured every hour using a digital thermometer. The procedure was repeated for each power level.

\subsection{Determination of induction time}

Induction time for crystallization was determined by UVS (UV 1800) ${ }^{18)}$. Samples (3 mL) were incubated at $T_{c}$ in 1 $\mathrm{cm}$ glass cuvettes, and absorbance values at $500 \mathrm{~nm}$ were recorded every $30 \mathrm{~s}$.

\subsection{Kinetic analysis}

\subsubsection{Determination of crystal growth rate}

Assuming that the crystal growth rate is constant in a period of time, the crystal growth rate could be calculated by the following equation ${ }^{19)}$.

$$
\mathrm{Rg}=\frac{d M c}{A d t}
$$

Where Rg is the crystal growth rate $\left(\mathrm{g} \cdot \mathrm{cm}^{-2} \cdot \mathrm{h}^{-2}\right), \mathrm{Mc}$ is the mass of the crystal deposited on the cold surface of the double-wall beaker $(\mathrm{g})$, A is the surface area of the cold surface of the double-wall beaker $\left(\mathrm{cm}^{2}\right)\left(\mathrm{A}=2 \pi \mathrm{rL}+\pi \mathrm{r}^{2}\right)$, and $t$ is the crystallization time $(\mathrm{h})$.

2.8.2 Avrami crystallization kinetics

The VCO composition is complex, even the crystallization of samples is more complex. Furthermore, data from isothermal crystallization do not conform to the first law of thermodynamics. Preliminary results showed that the experimental value of the isothermal crystallization was simulated to characterize the crystallization kinetics of VCO with the help of the Avrami equation as follows ${ }^{20)}$ :

$$
X \mathrm{t}=1-\exp \left(-k t^{n}\right)
$$

Where $\mathrm{Xt}$ is the relative crystallinity; $k$ is a composite rate constant for nucleation and crystal growth rate; and $n$ is the Avrami exponent, which represents the growth dimensionality and the nucleation type. According to the samples of the DSC test curve information, Xt could be calculated from DSC information, and Xt could be calculated via the following equation:

$$
X t=\frac{\Delta H_{t}}{\Delta H_{\text {total }}} \times 100=\frac{\Delta S F C_{t}}{S F C_{0}} \times 100
$$

Where $\Delta \mathrm{H}_{\mathrm{t}}$ is the crystallization heat at a given time $t$; $\Delta \mathrm{H}_{\text {total }}$ is the crystallization heat at the time of infinity; $\mathrm{SFC}_{\mathrm{t}}$ is the solid fat content (SFC) at a given time $t$, and $\mathrm{SFC}_{0}$ is the SFC at the time of infinity, which equals the SFC upon reaching equilibrium.

\subsection{Crystal microstructure by PLM}

The crystal microstructure was studied by PLM (Leica DMRX, Leica, Germany), with a microscope attached to a digital camera. The slide was pre-conditioned at the measurement temperature. One drop of sample was applied onto this slide covered with a cover glass, and the slide was placed on the stage for crystal microstructure observation. A photomicrograph was obtained at $200 \times$ magnification. Each photomicrograph presented a typical field for the measured sample.

\section{Statistical analyses}

All experiments were performed in triplicate, and results were reported mean values \pm standard deviations. Statistical analyses of the data were evaluated by one-way analysis of variance using SAS software.

\section{Results and discussion}

\subsection{Fatty acid compositions}

The kind and quantity of fatty acids in virgin coconut oil were shown in Table 1. As shown in Table 1, eight main components, including seven saturated fatty acids and one

Table 1 The kind and quantity of fatty acids in virgin coconut oil.

\begin{tabular}{cc}
\hline Fatty acid & \multicolumn{1}{c}{ Range $(\%)$} \\
\hline C $6: 0$ & $0.72 \sim 0.80$ \\
C $8: 0$ & $3.90 \sim 4.21$ \\
C $10: 0$ & $7.61 \sim 7.89$ \\
C $12: 0$ & $43.81 \sim 46.10$ \\
C $14: 0$ & $17.35 \sim 18.78$ \\
C $16: 0$ & $10.09 \sim 11.22$ \\
C $18: 0$ & $2.21 \sim 2.50$ \\
C $18: 1$ & $7.10 \sim 7.67$ \\
\hline
\end{tabular}


monounsaturated fatty acids were identified. Both the saturated and unsaturated fatty acids were found in the VCO samples. Among the fatty acids, lauric acid C12:0 (43.81 46.10\%), myristic acid C14:0 (17.35 18.78\%) and palmitic acid C16:0(10.09 11.22\%) were the most predominant saturated fatty acids, and oleic acid C18:1(7.10 7.67\%) was the principal monounsaturated fatty acids. The total amount of saturated fatty acids was approximately $90 \%$.

Coconut oil can be regarded as a multi-component mixture of various triglycerides containing more than $43 \%$ lauric acid and more than $12 \%$ of $\mathrm{C} 6: 0, \mathrm{C} 8: 0$ and $\mathrm{C} 10: 0$ fatty acids and more than 29\% of C14:0, C16:0, and C18:0 fatty acids. These differences in fatty acid composition influence the thermal behavior and crystallization properties. Therefore, it has a wide range to the melting point. According to this characteristics of $\mathrm{VCO}$, ultrasonic and temperature gradient field were applied to study the crystallization behavior of VCO.

\subsection{Thermal study of VCO}

The isothermal crystallization and re-melting profile of VCO were studied by DSC. The method showed the profile within the temperature range of $13^{\circ} \mathrm{C}-19^{\circ} \mathrm{C}$ as presented in Fig. 2. In Fig. 2a, the crystallization exothermal broadened with temperature increased, indicating a prolonged crystallization process. Meanwhile, Fig. 2b showed the reheating cycle after isothermal crystallization. As expected, the melting endotherms reduced with increases in $T_{c}$ because the high-melting-point fraction of VCO crystallized. The wider crystallization endotherms revealed that lower temperature led to the co-crystallization phenomena of triglycerides. The shoulders of the crystallization endotherms showed the co-crystallization of low-melting-point triglycerides at a crystallization temperature of $17^{\circ} \mathrm{C}$ and $19^{\circ} \mathrm{C}^{211}$.

The DSC study of the isothermal crystallization and reheating cycle of VCO could provide useful information for process design. It provided the melting point of VCO and measured the SFC at different crystallization temperature. Based on these experiments, VCO crystallization was performed at an appropriate crystallization temperature to achieve useful information and explain unknown phenomena in VCO testing.

\subsection{Effect of ultrasonic application on the induction time of VCO}

The induction time of grease refers to the time at which the first crystal is observed. The induction time is usually measured using pulsed nuclear magnetic resonance $\left(p\right.$-NMR) and $\mathrm{UVS}^{22}$. However, $p$-NMR exhibits a relatively low sensitivity under low SFC contents. Therefore, UVS was chosen for the study of the induction time ${ }^{18)}$.

The induction times of virgin coconut oil at different temperature under ultrasonic power of 0 and $36 \mathrm{~W}$ are shown in Table 2. The melting point of VCO was $25.0 \pm$
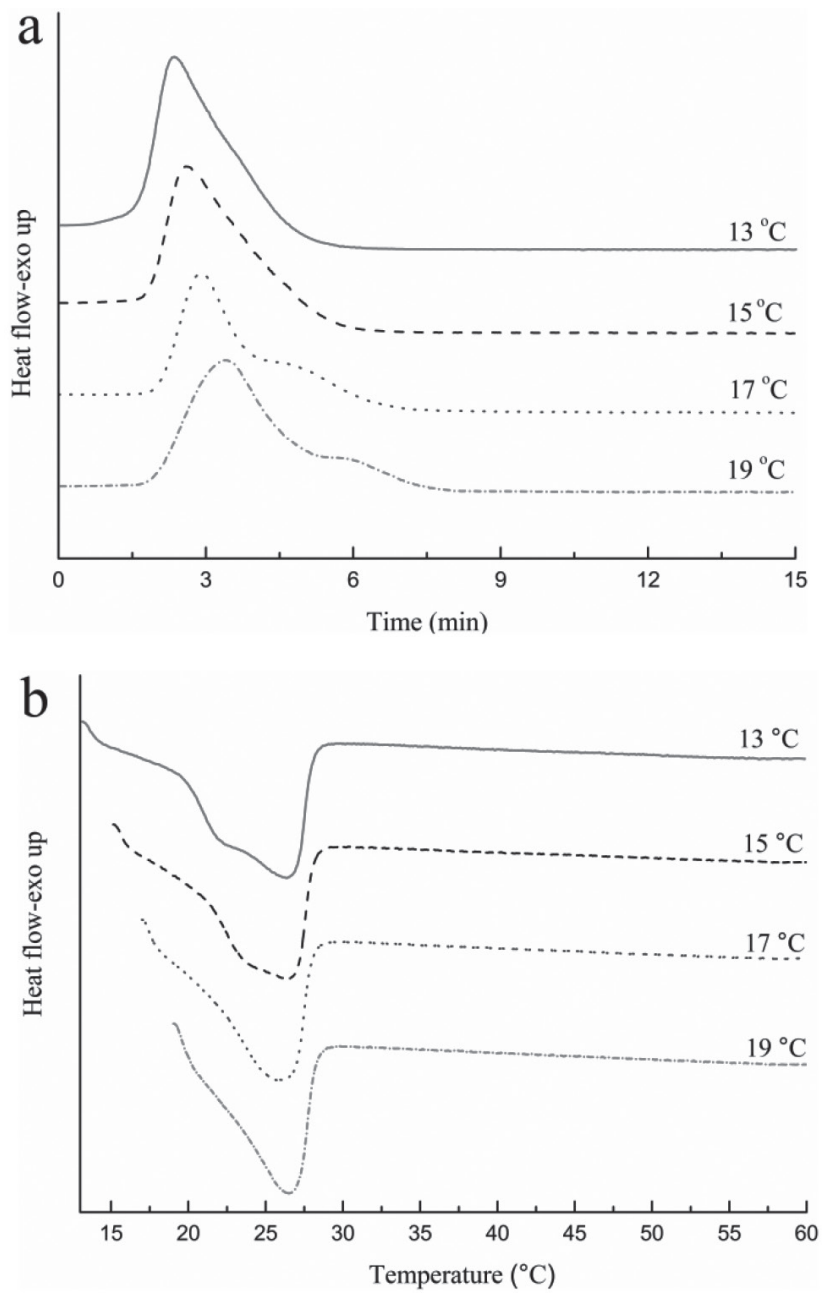

Fig. 2 (a) Isothermal crystallization peaks of VCO detected at different crystallization temperatures, (b) Reheating profile of VCO after isothermal crystallization.

$0.1^{\circ} \mathrm{C}$, which was measured by DSC. In order to study the crystallization behavior of VCO at low temperatures, the $T_{c}$ for this study were chosen $13,15,17$, and $19^{\circ} \mathrm{C}$ as the research temperature factor. The induction times for the samples crystallized at $13,15,17$ and $19^{\circ} \mathrm{C}$ without ultrasonic application were $0,1.3 \pm 0.2,3.0 \pm 0.3$ and $8.2 \pm 0.5$ min, respectively. However, when ultrasonic treatment $(36$ W) was given, the induction times shortened to $0,0.8 \pm 0.2$, $1.4 \pm 0.4$, and $3.6 \pm 0.3 \mathrm{~min}$, respectively. These results suggested that ultrasonic application significantly reduced the induction time. As expected, the induction time increased with increases of $T_{c}$, because the driving force was decreased. Ultrasonic treatment significantly reduced the induction time and accelerated the crystallization rate at operating temperatures above $15^{\circ} \mathrm{C}$, but no significant effects was observed at $13^{\circ} \mathrm{C}$ because of high super-cooling.

Table 3 shows the effect of ultrasonic power on the induction time of VCO at a crystallization temperature of 
Table 2 The induction times of virgin coconut oil at different temperature under ultrasonic power of 0 and $36 \mathrm{~W}$.

\begin{tabular}{ccc}
\hline \multirow{2}{*}{$\begin{array}{c}\text { Temperature } \\
\left({ }^{\circ} \mathrm{C}\right)\end{array}$} & \multicolumn{2}{c}{ Induction time $(\mathrm{min}){ }^{\mathrm{A}}$} \\
\cline { 2 - 3 } 13 & ultrasonic power 0 W & ultrasonic power $36 \mathrm{~W}$ \\
15 & $1.3 \pm 0.08^{\mathrm{a}}$ & 0 \\
17 & $3.0 \pm 0.22^{\mathrm{b}}$ & $0.8 \pm 0.05^{\mathrm{a}}$ \\
19 & $8.2 \pm 0.42^{\mathrm{c}}$ & $1.4 \pm 0.12^{\mathrm{b}}$ \\
\hline
\end{tabular}

${ }^{\mathrm{A}}$ Assays were performed in triplicate. Mean \pm SD values in the same column with different superscript letter are significantly different $(p<0.05)$.

Table 3 The effect of ultrasonic power on the induction times of virgin coconut oil at $19^{\circ} \mathrm{C}$.

\begin{tabular}{cc}
\hline Ultrasonic power $(\mathrm{W})$ & Induction time $(\mathrm{min})^{\mathrm{A}}$ \\
\hline 0 & $8.2 \pm 0.42^{\mathrm{a}}$ \\
12 & $5.0 \pm 0.33^{\mathrm{b}}$ \\
24 & $3.9 \pm 0.29^{\mathrm{c}}$ \\
36 & $3.6 \pm 0.23^{\mathrm{cd}}$ \\
48 & $2.8 \pm 0.18^{\mathrm{de}}$ \\
60 & $2.6 \pm 0.15^{\mathrm{e}}$ \\
\hline
\end{tabular}

${ }^{\mathrm{A}}$ Assays were performed in triplicate. Mean $\pm \mathrm{SD}$ values in the same column with different superscript letter are significantly different $(p<0.05)$.

$19^{\circ} \mathrm{C}$. It was observed that the induction time of VCO shortened significantly when the power level increased from 0 to $60 \mathrm{~W}$. Similar results were also found at lower temperature, ultrasonic application may increase the driving force at the nucleation stage ${ }^{13)}$. Ultrasonic mechanical action and cavitation effect may promote crystal formation and reduce the nucleation induction time. However, researchers held different opinions on the mechanism and cavitation effect by which ultrasonic application affects crystallization $^{23)}$. One scholar deems that the ultrasonic cavitation effect hastens the formation of crystal nucleus and the mechanical effect accelerates the crystallization rate $^{24)}$. However, most investigators speculate that cavitation plays an important role ${ }^{8,11)}$. When liquid is exposed to ultrasound, microscopic gas bubbles form. When the ultrasonic intensity exceeds the cavitation threshold, the bubbles become unstable, rapidly grow, and collapse violently within a sound cycle. Given the results presented above, it explained the effect of ultrasonic application on nucleation by these small bubbles, which provided numerous nucleation sites that promoted crystallization in the fat. As a result, induction time was significantly reduced.

\subsection{Effects of ultrasonic application on crystal growth rate} The results in Fig. 3 suggested that the effect of ultra-
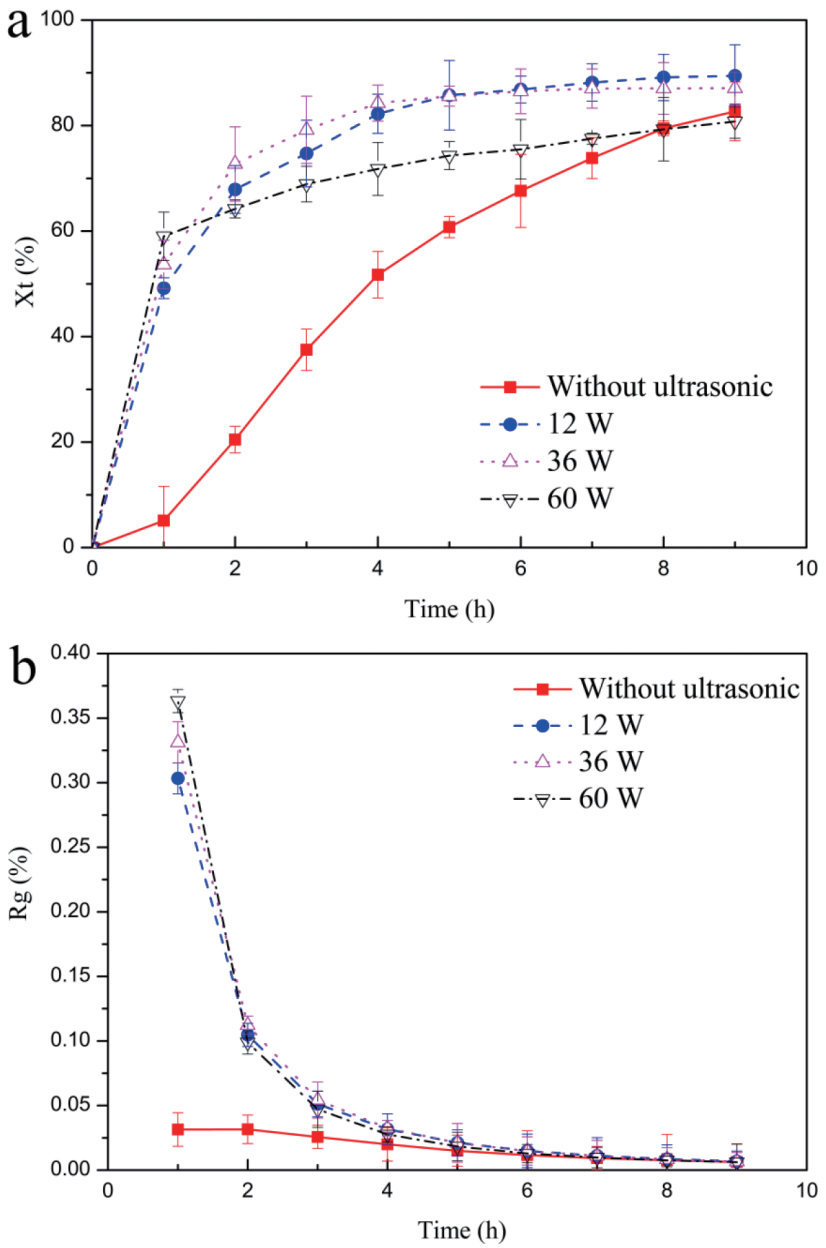

Fig. 3 Crystallization rate(a) and the relative degree of crystallinity curves (b) of virgin coconut oil without and with different ultrasonic power level at12, 36 and $60 \mathrm{~W}$, respectively. $T_{c}=19^{\circ} \mathrm{C}$. Rg, crystal growth rate; $\mathrm{Xt}$, relative crystalline.

sonic treatment was highly dependent on ultrasonic power levels. Chen et $a l^{14)}$ found that the higher power of ultrasonic application exerted a greater effect on promoting the crystallization of palm oil. This result may be explained by the strengthening of the power level of the applied ultrasonic field and the enhancement of cavitation and mechanical effect. However, compared with 12 and 36 W, 90\% relative crystallinity was not achieved when the ultrasonic power level was raised to $60 \mathrm{~W}$ (Fig. 3a). This observation indicated that ultrasonic application might exert other influences besides of nucleation induction, particularly, a thermal effect. Studies suggested that the rise in sample temperature was related to the ultrasonic power ${ }^{25)}$. The ultrasonic power played a critical role in the changes of oil temperature. These facts implied that higher ultrasonic power exerted a greater effect on crystallization; the thermal effect generated by the ultrasonic treatment was more pronounced as well, which was undesirable for the 
crystallization.

\subsection{Isothermal crystallization kinetics}

Crystallization temperature is an important parameter of oil/fat, and relative crystallinity reflects the crystallization rate and process. In this section, the effects of ultrasonic treatment at different $T_{c}$ were studied. The crystallization rates of VCO at different $T_{c}$ are shown in Fig. 3b. When samples were crystallized at $13^{\circ} \mathrm{C}$, the results were similar to those noted in the tests on induction time (Table 2). However, ultrasonic treatment indeed accelerated the crystallization rate and shortened the crystallization at the operating temperature of $13^{\circ} \mathrm{C}$ (Fig. $4 \mathrm{~d}$ ). The crystallization rate of $\mathrm{VCO}$ at $15^{\circ} \mathrm{C}$ (Fig. 4c) under ultrasonic treatment was significantly faster than without ultrasonic treatment. Similarly, increases at 17 and $19^{\circ} \mathrm{C}$ were significant(Fig. 4b and $\mathrm{a}$, respectively). The relative crystallinity data were fitted to the Avrami equation(1), and parameters of $k$ and $n$ were plotted versus $T_{c}$ for the samples with and without ultrasonic treatment (Fig. 4). A good fit to equation(1) was attained at all $T_{c}\left(R^{2}>0.98\right)$.

Figure 5 showed the effect of temperature on Avrami constant $(k)$ with and without ultrasonic treatment. Avrami
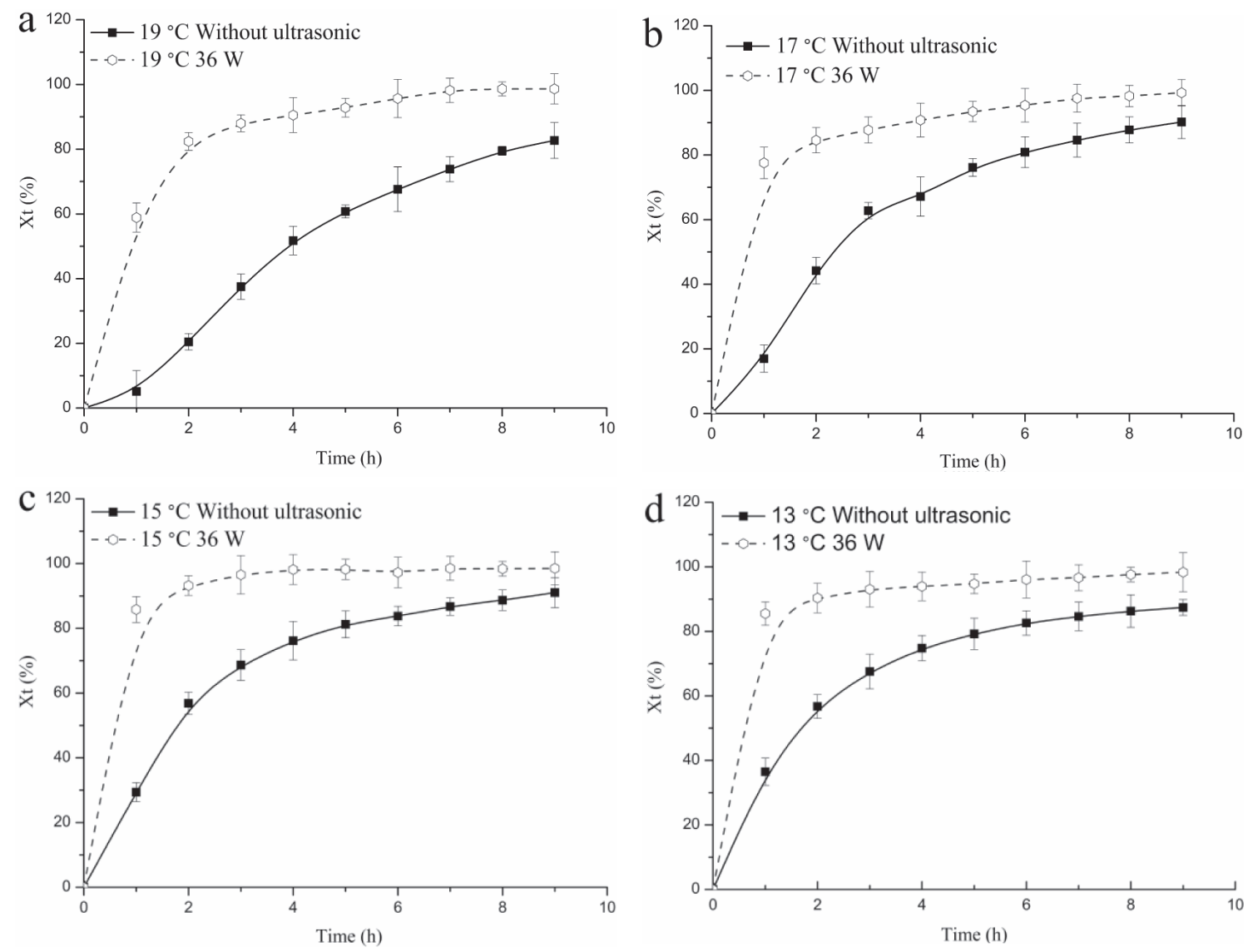

Fig. 4 The relative degree of crystallinity curves of virgin coconut oil at 13, 15,17 and $19^{\circ} \mathrm{C}$, respectively. Xt, relative crystallinity.

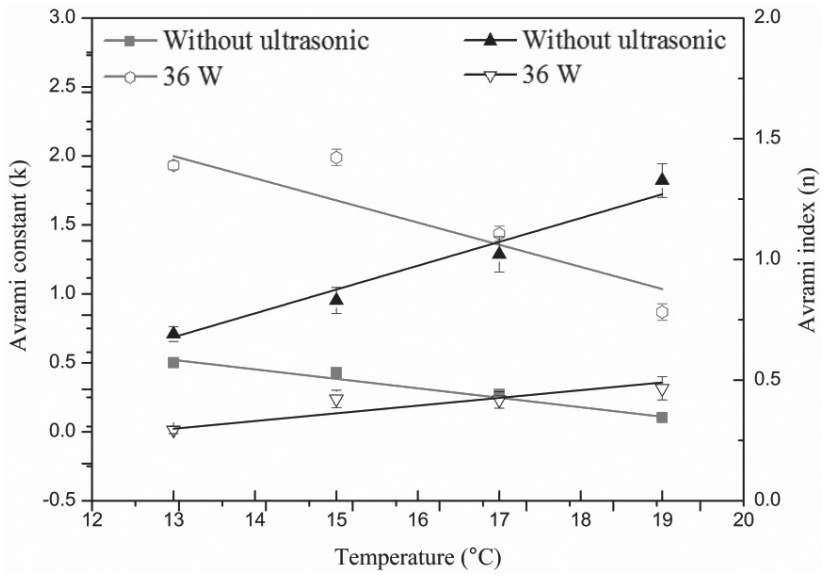

Fig. 5 Temperature dependence of the Avrami constant $k$ (red line) and Avrami index $n$ (black line) of virgin coconut oil crystallized without ultrasonic and with ultrasonic at $36 \mathrm{~W}$.

constant was decreased gradually as the temperature increased. However, the Avrami constants $(k)$ of sonicated VCO were significantly higher than those of control samples, most notably at higher temperatures. At $13^{\circ} \mathrm{C}$, 
Avrami constant with and without ultrasonic treatment of VCO are $0.502 \pm 0.023$ and $1.931 \pm 0.031$, respectively. At $19^{\circ} \mathrm{C}$, Avrami constant with and without ultrasonic treatment of VCO are $0.104 \pm 0.013$ and $0.869 \pm 0.060$, respectively. It indicated that ultrasonic accelerate crystallization rate obviously in high crystallization temperature. At low temperature $\left(13^{\circ} \mathrm{C}\right)$, ultrasonic application increased the Avrami constant by approximately 3.9 times. By contrast, at $19^{\circ} \mathrm{C}$, ultrasonic application increased the Avrami constant by approximately 8.3 times. The Avrami exponent $(n)$, which is a function of the number of dimensions at which growth takes place and reflects the details of nucleation and growth mechanisms, behaves differently at different $T_{c}$. As shown in Fig. 5, Avrami exponent $(n)$ was increased gradually as the temperature increased. For $T_{c}=$ 17 and $19^{\circ} \mathrm{C}$, the $n$ for the samples without ultrasonic treatment were $1.327 \pm 0.071$ and $1.021 \pm 0.073$, respectively. It indicated that the growth of the crystal was mixture of plate-like and needle-like. But, the $n$ of VCO under ultrasonic treatment were less than 1with temperature range $17^{\circ} \mathrm{C}$ to $19^{\circ} \mathrm{C}$, implying that ultrasonic treatment transformed the mixed growth of plate-like and needle-like into needle-like growth ${ }^{26)}$. Therefore, ultrasonic treatment offered an important contribution to the crystallization mechanism. However, at $T_{c}=15^{\circ} \mathrm{C}$ and $13^{\circ} \mathrm{C}$, the $n$ for the samples with and without sonication were less than 1 , indicating a needle-like crystal growth. These observations suggested that the effect of ultrasonic treatment on crystallization was greatly dependent on the super-cooling degree, and a proper temperature range existed within which ultrasonic application significantly changed the crystallization behavior of VCO.

However, previous studies reported a delay in oil crystallization when ultrasonic application was conducted at extremely low temperatures ${ }^{12}$. This result may be due to a slight increase in oil temperature during the process as substantially explained by some studies ${ }^{11)}$. At low supercooling, the quantity of available growth units in the vicinity of the crystal surface is small. Under these conditions, the grease crystal particle transfer becomes rate limiting in supplying growth units to the crystal surface; however, ultrasonic treatment enhances the crystal particle transfer in the oil. By contrast, at high super-cooling, the temperature is expected to be the primary factor inducing crystallization; thus, the effect of ultrasonic treatment is limited. When the crystallization time is more than $9 \mathrm{~h}$, the experiments have achieved the same quantitative SFC at definite temperatures (Fig. 3a). This finding implied that ultrasonic treatment evidently reduced the time to reach equilibrium without changing the SFC for the same oil temperature.

\subsection{Effect of ultrasonic treatment on the microstructure of crystals \\ The crystallization rate is always closely related to the}

microstructure of oil/fat. Given that ultrasonic treatment promoted the nucleation induction time and crystallization rate, the effects on the microstructure of VCO were studied during crystallization in the presence and absence of ultrasonic treatment.

The Avrami exponent $n$, which is a function of the number of dimensions at which growth takes place and reflects the details of nucleation and growth mechanisms, behaves differently at different $T_{c}^{27}$. The Avrami exponent $\mathrm{n}$ of the VCO increased as a function of temperature, whereas the sonicated VCO attained a lower $n$ value than the control VCO. Figure 6 shows the morphology of the VCO crystallized at $19,17,15$, and $13^{\circ} \mathrm{C}$ with and without ultrasonic treatment. Ultrasonic application was shown to significantly affect the microstructure of the VCO crystals on the crystal cluster shape and size. When VCO crystallized without ultrasonic treatment, a continuous increase in crystal size was observed and the resultant clusters assumed plate-like and needle-like shapes at 17 and $19^{\circ} \mathrm{C}$. At $36 \mathrm{~W}$ ultrasonic application, at a certain time, the amount of crystals significantly increased. The crystal aggregates produced under ultrasonic treatment became smaller, and the clusters were needle-like in shape.

The effects of ultrasonic treatment on the microstructure of VCO at different $T_{c}\left(15\right.$ and $\left.13^{\circ} \mathrm{C}\right)$ were also evaluated, and results are shown in Fig. 5 . At 13 and $15^{\circ} \mathrm{C}$, no significant difference was observed in the presence and absence of ultrasonic treatment. This occurrence may be related to the dominant role that high super-cooling played in VCO crystallization over ultrasonic treatment. Combined with the phenomena observed in Figs. 5 and 6, the cavitation and mechanical effects of ultrasonic treatment not only weakened the links among oil crystals but also altered the crystal forms. Simultaneously, the smaller sizes of crystals reduced the sedimentation velocity and finally led to the distribution of homogeneous crystal.

On the basis of the microstructure, the coconut oil crystallization process was observed. Several conclusions can be drawn from this study: (1) the crystallization behavior of VCO blends strongly depends on temperature and ultrasonic treatment. (2) the ultrasonic and temperature affects not only the structure of crystals formed but also the amount of crystals obtained, accelerating the crystallization process. Under the crystallization temperature of $19^{\circ} \mathrm{C}$, the use of ultrasonic accelerated the process of crystallization. Moreover, the crystal size of the product was fine and homogeneous, and crystal structure was dense. There was no difference in the absence and presence of ultrasonic treatment under the crystallization temperature of $15^{\circ} \mathrm{C}$. However, the crystal structure of control sample was looser and the grains of crystal were larger when the crystallization temperature above $15^{\circ} \mathrm{C}$. 

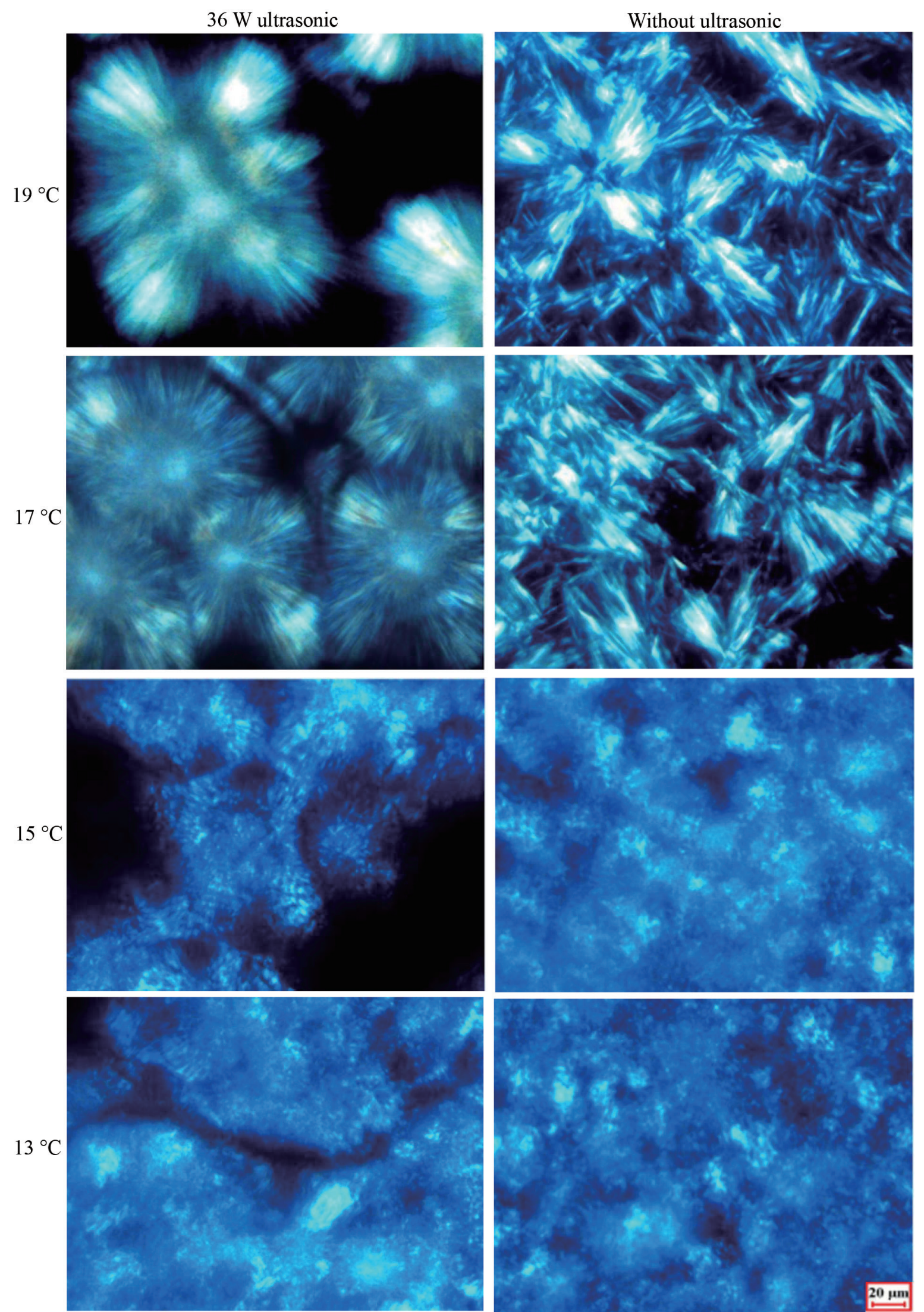

Fig. 6 Microstructure of virgin coconut oil crystallized at 19, 17, 15 and $13^{\circ} \mathrm{C}$ without and with ultrasonic treatment. 


\section{Conclusions}

The effect of ultrasonic conditions on the nucleation and growth of VCO crystals in a temperature gradient field was studied using DSC, ultraviolet/visible spectrophotometry and polarized light microscopy. Results showed that the crystallization and nucleation rates increased as a function of ultrasonic power at $T_{c}$ values above $15^{\circ} \mathrm{C}$. However, no significant difference was observed on the nucleation rate of VCO at $13^{\circ} \mathrm{C}$ because of high super-cooling. According to the experimental data, the crystallization rate constant $k$ of VCO under ultrasonic treatment was significantly greater than that without ultrasonic treatment. Ultrasonic treatment may accelerate crystal growth rate and shorten crystallization. By simulating the Avrami equation to the crystallization process, a goodness of fit greater than 0.98 was attained, and the application of the Avrami equation to crystallization with ultrasonic treatment was reasonable. The experimentally determined Avrami exponent $n$ and the VCO crystal morphology showed that ultrasonic treatment changed the crystallization mechanism of VCO by producing smaller and more uniform crystals.

\section{Acknowledges}

This study work was supported by the Natural Science Foundation of the Republic of China(No.31160325); the Natural Science Foundation of Hainan province (No. 20153159, No. 314075); and supported by the Research Foundation of Education Bureau of Hainan Province, China (Grant No. Hnky2016ZD-1).

\section{References}

1) Villarino, B.J.; Dy, L.M.; Lizada, M.C.C. Descriptive sensory evaluation of virgin coconut oil and refined, bleached and deodorized coconut oil. LWT-Food Sci Technol. 40, 193-199(2007).

2) Marina, A.M.; Man, Y.B.C.; Amin, I. Virgin coconut oil: Emerging functional food oil. Trends. Food Sci. Technol. 20, 481-487 (2009).

3) Marikkar, J.M.N.; Saraf, D.; Dzulkifly, M.H. Effect of fractional crystallyzation on composition and thermal behavior of coconut oil. Int. J. Food Prop. 16, 12841292 (2013).

4) Jia, Y.Y.; Peng, J.; Xu, F.L.; Li, R.; Xia, Q.Y.; Bai, X.P. Influence of sorbitan trioleate on crystallization kinetics of palm oil. Int. Proc. Chem. Biol. Environ. 50, 163168 (2013).

5) Su, N.; Li, Y.; Bai, X.; Zhang, Y.; Liu, H.; Li, J.; Jie, P. Isothermal crystallization kinetics of palm oil with additives. AJ FST. 7, 768-772 (2015).

6) Ulrich, J. Is melt crystallization a green technology?
Cryst. Growth Des. 4, 879-880(2004).

7) Farid, C.; Muhammed Kamran, K. Applications of ultrasound in food technology: Processing, preservation and extraction. Ultrason. Sonochem. 18, 813-835 (2011).

8) Chow, R.; Blindt, R.; Chivers, R.; Povey, M. A study on the primary and secondary nucleation of ice by power ultrasound. Ultrasonics 43, 227-230 (2005).

9) Chow, R.; Blindt, R.; Chivers, R.; Povey, M. The sonocrystallisation of ice in sucrose solutions: primary and secondary nucleation. Ultrasonics 41, 595-604 (2003).

10) Normah, I.; Cheow, C.S.; Chong, C.L. Crystal habit during crystallization of palm Oil: Effect of time and temperature. Int. Food Res. J. 20, 417-422(2013).

11) Castro, L.D.; Priego-Capote, F. Ultrasound-assisted crystallization (sonocrystallization). Ultrason. Sonochem. 14, 717-724(2007).

12) Martini, S.; Suzuki, A.H.; Hartel, R.W. Effect of high intensity ultrasound on crystallization behavior of anhydrous milk fat. J. Am. Oil Chem. Soc. 85, 621-628 (2008).

13) Suzuki, A.H.; Lee, J.; Padilla, S.G.; Martini, S. Altering functional properties of fats using power ultrasound. $J$. food Sci. 75, 208-214(2010).

14) Chen, F.; Zhang, H.; Sun, X.; Wang, X.; Xu, X. Effects of ultrasonic parameters on the crystallization behavior of palm oil. J. Am. Oil Chem. Soc. 90, 941-949 (2013).

15) Che Man, Y.B.; Suhardiyono; Asbi, A.B.; Azudin, M.N.; Wei, L.S. Aqueous enzymatic extraction of coconut oil. J. Am. Oil Chem. Soc. 73, 683-686(1996).

16) Mason, M.E.; Waller, G.R.; Chem, A. Dimethoxypropane induced transesterification of fats and oils in preparation of methyl esters for gas chromatographic analysis. Anal. Chem. 36, 583-586 (2002).

17) Macnaughtan, W.; Farhat, I.A.; Himawan, C.; Starov, V.M.; Stapley, A.G.F. A differential scanning calorimetry study of the crystallization kinetics of tristearin. $J$. Am. Oil Chem. Soc. 83, 1-9(2006).

18) Wright, A.J.; Narine, S.S.; Marangoni, A.G. Comparison of experimental techniques used in lipid crystallization studies. J. Am. Oil Chem. Soc. 77, 1239-1242(2000).

19) Chaleepa, K.; Szepes, A; Ulrich, J. Dry fractionation of coconut oil by melt crystallization. Chem. Eng. Res. Des. 88, 1217-1222 (2010).

20) Delattre, O.; Régnier, E.; Schuller, S.; Poissonnet, S.; Massoni, N.; Allix, M.; Matzen, G. Crystallization kinetics of apatite and powellite in a borosilicate glass under thermal gradient conditions. Phys. Proce. 48, 3-9 (2013).

21) Rao, R.; Sankar, K.U.; Sambaiah, K.; Lokesh, B.R. Differential scanning calorimetric studies on structured lipids from coconut oil triglycerides containing stearic acid. Eur. Food Res. Technol. 212, 334-343(2001). 


\section{Wu, J. Cao and X. Bai et al.}

22) Kashchiev, D.; Firoozabadi, A. Induction time in crystallization of gas hydrates. J. Cryst. Growth 250, 499$515(2003)$.

23) Patrick, M.; Blindt, R.; Janssen, J. The effect of ultrasonic intensity on the crystal structure of palm oil. $U l$ trason. Sonochem. 11, 251-255(2004).

24) Arends, B.J.; Blindt, R.A.; Janssen, J.; Patrick, M. Crystallization process using ultrasound. US Patent 6,630,185 B2 (2003).

25) Dean, K.; Krstina, J.; Tian, W.; Varley, R.J. Effect of ul- trasonic dispersion methods on thermal and mechanical properties of organoclay epoxy nanocomposites. Macromol. Mater. Eng. 292, 415-427 (2007).

26) Puppo, M.C.; Martini, S.; Hartel, R.W.; Herrera, M.L. Effects of sucrose esters on isothermal crystallization and rheological behavior of blends of milk-fat fraction sunflower oil. J. food Sci. 67, 3419-3426 (2002).

27) Peng, J.; Bai, X.; Zhang, Y.; Bai, X. Directional crystallization kinetics of coconut oil under temperature gradient. Global J. Sci. Front. Res. Chem. 12, 1-5(2012). 